\title{
Games: uma reflexão sobre contextos e sua influência na construção do futuro
}

Games: a reflection about contexts and their influence on the construction of the future

SANTOS, Filipe Mesquita dos; Mestrando; Universidade da Região de Joinville - UNIVILLE filipee.mesquita@gmail.com

SOBRAL, JOÃO E. C.; Dr.; Universidade da Região de Joinville - UNIVILLE

Sobral41@gmail.com

CAVALCANTI, Anna L. M. S. ; MsC; Universidade da Região de Joinville - UNIVILLE anna.cavalcanti08@gmail.com

\section{Resumo}

Este artigo é um relato de um recorte da dissertação em andamento no Mestrado Profissional em Design da Universidade da Região de Joinville (UNIVILLE), cujo objetivo é refletir sobre a influência dos games na construção do futuro. A pesquisa foi qualitativa quanto ao tratamento dos dados e descritiva quanto ao fenômeno tratado. A coleta de dados foi realizada por meio de pesquisa bibliográfica, em que aborda os games no contexto cultural e socioeconômico; enfatiza a evolução ao longo da história, com foco na interação entre jogos e jogadores. O Design foi abordado como (I) a ciência que estuda o mundo criado (pelo homem), conforme sugere Cross (1982), e como (II) 'designação', ou seja, o sentido e o valor dos produtos criados pelo homem situados em seu tempoespaço (CARDOSO 2016). As análises foram geradas a partir de cenários traçados para o futuro e a influência dos games nos cenários do advir.

Palavras Chave: jogos; vídeo games; cenários

\section{Abstract}

This article is a report of a recent dissertation of Professional Master in Design of the University of the Region of Joinville (UNIVILLE), whose objective is to reflect about the influence of the games in the construction of the future. The research was qualitative about the treatment of the data and descriptive for the phenomenon reported. Data collection was supported by bibliographic research, mainly about the games in the cultural and socioeconomic context; the evolution throughout history, with an interaction between games and players. Design was approached as a science that studies the created-world (by humans), as suggested by Cross (1982), and as 'designation', the meaning and value of man-made products in their time-space (CARDOSO 2016). The forests were generated from a series of scenarios for the future and an influence of the games in these scenarios.

Keywords: games; video games; scenarios 


\section{Introdução}

Atualmente são muitas as previsões e cenários que partem das crescentes pesquisas sobre a inteligência artificial. Alguns se mostram sombrios e outros estimulantes. Esta pesquisa busca antever cenários futuros relacionados aos games, com base no contexto e no cenário atual, com o objetivo de sugerir caminhos para o desenvolvimento de novos games, assim como a utilização dos games como soluções para os problemas futuros.

A metodologia utilizada envolveu a revisão bibliográfica sobre jogos, vídeo games e os contextos e tendências de futuro. Os resultados apresentados, neste artigo, estão baseados em uma postura fenomenológica, pois propõe análises fundadas na perspectiva do pesquisador, mestrando em design, com dissertação voltada aos games e suas utilizações.

Os jogos eletrônicos têm ampliado de forma exponencial sua utilização; fenômeno fundado na inteligência artificial. Estes avanços tecnológicos permitiram ganhos estéticos e funcionais que ampliaram a interatividade e a imersão. Atualmente estes aparatos passam a ser usados, não só no entretenimento, mas em outras atividades profissionais como, a medicina, engenharia, ensino, etc. Avaliar a relevância e o papel social que este aparato poderá desenvolver em possíveis cenários futuros, se mostra importante por si, pois permite a criação de estratégias que possam vir a ser desenvolvidas pelo design; portanto, apresenta-se como objetivo uma reflexão sobre possíveis cenários sociais futuro e a partir destes, analisar possíveis papeis a serem desempenhados pelos jogos eletrônicos.

Este artigo está organizado em quatro sessões: (1) Sobre o verbo 'jogar' - origem, caracterização e efeitos da prática; (2) Uma nova maneira de jogar: evolução e panorama atual; (3) Cultura, Sociedade e Mercado Gamer - público, fenômenos culturais, sociais e mercadológicos; e por fim, (4) Games e a Construção Futuro - paradigmas e a contribuição dos games.

O embasamento teórico utilizado neste artigo está fundado nos livros: 'A Realidade em Jogo - Por que os games nos tornam melhores e como eles podem mudar o mundo' escrito por McGonigal (2012), e 'Homo Deus - Uma breve história do Amanhã' escrito por Harari (2016). Outros autores, livros, notícias sobre games, design, cenários e dados de mercado foram utilizados como complemento à discussão construída neste artigo. Que os jogos comecem!

\section{Sobre o verbo 'jogar'}

Huizinga (2005) afirma que o jogo precede a cultura. Em seu livro 'Homo Ludens', o autor explica que enquanto a cultura é derivada da sociedade humana, os jogos o acompanham desde a sua origem, o que pode facilmente ser observado nos animais.

Bastará que observemos os cachorrinhos para constatar que, em suas alegres evoluções, encontram-se presentes todos os elementos essenciais do jogo humano. Convidam-se uns aos outros para brincar mediante um certo ritual de atitudes e gestos. Respeitam a regra que os proíbe morderem, ou pelo menos com violência, a orelha do próximo. Fingem ficar zangados e, o que é mais importante, eles, em tudo isto, experimentam evidentemente imenso prazer e divertimento (HUIZINGA, p.3, 2005).

A palavra 'brincar' aparece como sinônimo, parte ou resultado de um jogo. Na maior parte dos artigos e livros pesquisados sobre a jogos e vídeo games, foi possível identificar um apelo dos autores para que os jogos sejam abordados como algo sério, e não como ação apenas lúdica. $\mathrm{A}$ 
confusão com a palavra brincadeira surge desde a formação do vocabulário de alguns idiomas, como por exemplo o inglês, em que o verbo 'play' não distingue o que em português chamamos de 'jogar' e 'brincar'.

Desde Aristóteles o jogo era visto próximo à felicidade e à virtude, em outras palavras, atividades em si e não "necessárias" como trabalho, por exemplo. É desta forma que o jogo é visto. Kant o liga estritamente à estética e acredita que este favoreça a sensação de saúde e o divide em três grupos, os jogos de sorte; os musicais e os de pensamento, estes os propriamente estéticos, destacando a função biológica que serve para manter desperta a função vital. Na mesma linha, seguia Schiller ao estender o jogo a qualquer organismo vivo que busca a sobrevivência, a partir da falta de 'algo', se joga, e se brica quando se tem a plenitude. O jogo é, portanto, fim e meio em si mesmo. Este foi o conceito explorado no século XIX pela pedagogia que via o jogo como um adestramento para as atividades vitais e pela prática da vida. A pedagogia moderna e contemporânea o vê como uma forma privilegiada de formação humana. Para a psicologia ou a antropologia se destaca a função biológica e social, pois é para estas especialidades, fundamental a conservação e adaptação humana à sociedade. Para a estética o jogo tem analogia com a atividade artística. (ABBAGNANO, 1996)

Se após a formulação de Aristóteles, o conceito de Jogo não mudou em essência, o mesmo não aconteceu com o conceito de trabalho, este ligado a manualidade na filosofia antiga, e visto pela Bíblia como uma decorrência do pecado original e condição perpetua, obrigação e o sofrimento. $O$ trabalho transmutou ao longo da história e passou a se confundir com a própria natureza humana. Atualmente se distingue o trabalho imposto do trabalho voluntário, este último visto como manifestação de liberdade e felicidade.

Mas se o conceito de jogo não mudou tanto quanto o de trabalho, ao menos é possível, diante do pensamento filosófico transcorrido ao longo dos séculos que nos separa de Aristóteles, e da inter-relação que este propôs com o próprio trabalho, afirmar que seja qual for o período histórico, este se distancia de uma atividade inútil e voltada exclusivamente ao passar do tempo, conceito muitas vezes arraigado no senso comum. Contudo, não é possível tão pouco aceitar a oposição proposta por Aristóteles em colocar de um lado o trabalho e do outro, o jogo. Para ele a atividade lúdica se difere do trabalho por estar relacionada ao prazer intrínseco, à felicidade ou às atividades virtuosas, consequentemente ligada a atividade interna, enquanto o trabalho, por sua vez, estaria ligado a um fim e uma atividade externa. Na contemporaneidade, o conceito de trabalho pode ser visto como uma atividade lúdica e ligado a virtude e ao prazer. 0 jogo pode passar a ser em si um trabalho, e o trabalho muitas vezes torna-se prazeroso e lúdico.

O jogo, portanto, é tido como um recurso que possibilita a aprendizagem de várias habilidades. No processo de aprendizagem, as crianças podem colocar desafios para serem resolvidos por elas mesmas, e são capazes de criarem hipóteses para soluções dos problemas. Dessa maneira, os jogos são meios que contribuem e enriquecem o desenvolvimento intelectual. A atividade lúdica é, segundo Piaget, o berço obrigatório das atividades intelectuais (ALVES, L.; BIANCHIN, M.A.,2010).

Seguindo a metodologia fenomenológica, restam sempre perguntas, o que é realmente um jogo em si mesmo? De acordo com McGonigal (2012), os jogos apareceram em diversas plataformas, como campos, quadras de esporte, tabuleiros, cartas, eletrônicos e outros; em diversos gêneros (tipos de jogo) e possibilidade de serem jogados sozinhos, em duplas, em grupos 
e em multidões, no caso dos jogos online. Entre todas estas variedades, existe um conjunto de elementos essencialmente únicos que caracterizam a estrutura dos jogos e a experiência dos jogadores, pois um jogo é constituído de metas, regras, sistema de feedback e participação voluntária, que podem ser mais bem compreendidos no quadro 1 abaixo.

Quadro 1 - Constituição de um jogo e suas definições

i) Metas

É o resultado específico que os jogadores vão trabalhar para conseguir. Ela foca a atenção e orienta continuamente a participação deles ao longo do jogo. A meta propicia um senso de objetivo.

ii) Regras

Impõem limitações em como os jogadores podem atingir a meta. Removendo ou limitando as maneiras óbvias, as regras estimulam os jogadores a explorar possibilidades anteriormente desconhecidas para atingir o objetivo final. Elas liberam a criatividade e estimulam o pensamento estratégico.

iii) Sistema de Feedback

Diz aos jogadores o quão perto eles estão de atingir a meta. O sistema pode assumir a forma de pontos, níveis, placar ou barra de conhecimento de um resultado objetivo: "O jogo está concluído quando...". O feedback em tempo real serve como uma promessa para os jogadores de que a meta é definitivamente alcançável, além de fornecer motivação para continuar jogando.

iv) Participação Voluntária

Exige que cada um dos jogadores aceite, consciente e voluntariamente, a meta, as regras e o feedback. Isso estabelece uma base comum para múltiplas pessoas jogarem ao mesmo tempo. E a liberdade para entrar ou sair de um jogo por vontade própria assegura que um trabalho intencionalmente estressante e desafiador é vivenciado como uma atividade segura e prazerosa.

Fonte: adaptado de Realidade em Jogo (MCGONIGAL, 2012)

Os jogos envolvem seus usuários como uma obsessão, pois os estimulam apenas por estresses positivos a se superarem, e quando alcançam a meta, gozam da satisfação de conquistar algo que a realidade, muitas vezes, não oferece. McGonigal $(2012$, p.32) supõe que "em comparação aos jogos, a realidade é muito fácil. Os jogos nos desafiam com obstáculos voluntários e nos ajudam a empregar nossas forças pessoais da melhor forma possível". O filósofo francês Baudrillard (1991), caracterizou um jogo como uma grande fonte de simulações. Ele apresentou os conceitos de simulacros e simulações pela primeira vez em 1981 (Quadro 2), refletindo sobre a atuação das forças dos valores e significados sobre a cultura, a sociedade e o mercado, apesar de não ter feito nenhuma menção aos jogos ou vídeo games, suas teorias vão de acordo com as de McGonigal quando a mesma explica o porquê jogamos.

Quadro 2 - Principais Conceitos do livro Simulacros e Simulações

i) Simulacro

Portadores tangíveis ou intangíveis de signos/significados, valores.

ii) Simulação

Apoiando-se nos mais diversos simulacros, as simulações podem ser tão perfeitas quanto a realidade, fazendo-nos acreditar que a simulação é real. Aqueles que fazem parte da simulação saberem que distinguem a simulação da realidade. 
iii) Hiper Realidade

Quando a simulação é perfeita, chama-se de hiper-realidade. Uma simulação construída por meio de simulacros coesos de forma a não deixar aqueles imersos na simulação distingui-la da realidade.

iv) Significação

\begin{abstract}
Para que o simulacro tenha o mesmo sentido para os participantes das simulações, o processo de significação dos mesmos deve ser comum entre eles. O valor simbólico 'inicial', quando o objeto é recém dotado de um novo significado, é frágil se comparado a um signo cujo seu processo simbólico é uma construção sobre outros objetos simbólicos.
\end{abstract}

Fonte: adaptado de Simulacros e Simulações (BAUDRILLARD, 1991)

Quando um ou mais jogadores aceitam participar de um jogo, todos passam a concordar com um sistema de significação em comum: ganhar o jogo, significa alcançar a meta. A meta pode não ter nenhum valor ou função para a realidade, mas dentro do jogo, simulacro que possui uma narrativa própria, todos os participantes imergem na simulação passando a valorizar a meta conforme a narrativa estabelecida. Diferente da realidade, no jogo, o usuário sabe exatamente onde quer chegar, direcionando seus esforços em prol daquele objetivo e assim, atingindo o estado de 'fluidez', conforme a teoria do fluxo de Csíkszentmihályi (apud MCGONIGAL, 2012).

De acordo com a teoria do fluxo, a felicidade humana também está relacionada a superação de obstáculos. O esforço empregado em superar tais obstáculo é chamado pelo autor de 'trabalho árduo'. É um engano acreditar que 'trabalho' está relacionado apenas as atividades com fins profissionais/produtivos. O trabalho árduo pode ser empregado em qualquer situação em exija de alguém o empenho para superar desafios. O estado de fluidez é quando alguém está sistematicamente superando desafios com envolvimento e otimismo, assim, eleva-se a motivação para mais e mais momentos de desafios e superações. Já o contrário, quando os obstáculos não são superados e não há a esperança de superação, gera o sentimento de frustração. $O$ trabalho árduo estruturado é altamente motivador, da mesma forma que um jogo se propõe a ser, traz a "mais elevada forma de felicidade disponível para os seres humanos: envolvimento intenso e otimista com o mundo a nossa volta" (Ibidem, p. 42).

Os jogos podem trazer trabalho de grandes desafios, trabalho de distração, trabalho mental, trabalho de descoberta e trabalho criativo. É sabido que qualquer pessoa, em qualquer situação de trabalho e superação de objetivos pode acessar o estado de fluidez, porém, MgGonigal (2011) apresenta os jogos como uma fonte óbvia de fluxo: metas que podem ser customizadas para os jogadores e obstáculos de acordo com o nível de cada jogador tornam até mesmo a frustração do fracasso em combustível para a superação, dentro do ambiente simulado, seja jogo eletrônico ou de tabuleiro, de cartas ou esportivo.

Dentre os benefícios dos jogos McGonigal (2012) acrescenta, da mesma forma, dois fatores para o bem-estar dos jogadores sob a ótica da psicologia positiva: o fiero e o otimismo flexível.

O fiero, palavra italiana que se refere ao orgulho, é o sentimento do trunfo sobre a adversidade, e provavelmente um dos sentimentos mais instintivos dos humanos, uma vez que humanos de diferentes culturas sentem o fiero nas mesmas circunstâncias, e o manifestam com os mesmos movimentos físicos: elevação dos punhos para o alto, elevação da cabeça e expressões de vitória. Já o otimismo flexível, a autora apresenta como o oposto da depressão. Quando em depressão, a pessoa auto avalia sua vida sob o prisma do tédio e da ansiedade, sentindo-se 
desestimulada a perseguir uma nova e melhor condição, ou até mesmo se sente incapaz de imaginar uma vida melhor. Os jogos seriam o oposto da depressão porque o jogador sabe onde quer chegar, e pode ainda calibrar suas expectativas em relação as suas habilidades versus os obstáculos, tornando-o superpoderoso para o alcance de metas e estabelecimento de novos desafios.

\section{Uma nova maneira de jogar: evolução e panorama atual}

Ao dizer que o jogo precede a cultura, Huizinga (2005) deixa claro que não é possível datar a origem precisa da prática de jogar. Já os vídeo games, ou plataformas eletrônicas para jogos, são produtos do homem contemporâneo, com pouco mais de 40 anos de existência.

De acordo com Ervin (2017), em seu livro 'Bit by Bit' que contextualiza a história dos vídeos games, o primeiro jogo eletrônico foi criado pelo físico americano Higinbotham em 1958. Um dos criadores da bomba atômica na Segunda Guerra Mundial, programou o jogo para um radar que fora feito para interceptar mísseis inimigos, utilizando o osciloscópio como vídeo, o qual deu o nome de 'Tennis for Two' (FIGURA 1). No entanto, entre os primeiros jogos eletrônicos criados e o primeiro comercializado para a população, houve um hiato de 14 anos após o radar de Higinbotham.

Figura 1 - Tennis for Two no Osciloscópio do Radar

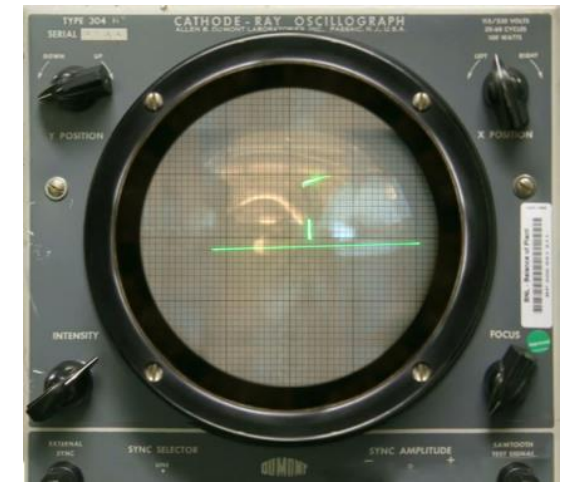

Fonte: Brookhaven National Laboratory (web,2013) ${ }^{1}$

Em 1972, quando o engenheiro eletrônico Ralph Baer teve a ideia de criar um aparelho que fosse capaz de executar jogos eletrônicos por meio da televisão, surge de fato, o primeiro console, aparelho de vídeo game, batizado de Odissey. Este aparelho foi produzido e comercializado pela empresa Magnavox. Já o nome 'vídeo game' surgiu da junção das palavras 'game', 'jogo' em inglês; e 'vídeo' como uma referência à televisão utilizada para reproduzir as imagens.

Portanto, entende-se por vídeo game o jogo eletrônico distribuído por mídia física ou digital. Os jogos eletrônicos podem ser executados em diversas plataformas, sendo as principais: console, aparelho ligado a televisão; o console portátil, aparelho com áudio e vídeo integrados; computadores e celulares (LUZ, 2010; ERVIN, 2017). No decorrer dos anos, novos consoles surgiram com novas tecnologias, ampliando a capacidade de interação e processamento gráfico. Assim,

\footnotetext{
${ }^{1}$ Brookhaven National Laboratory. Disponível em: <https://www.bnl.gov/about/history/firstvideo.php>. Acesso em: 26 mar. 2018
} 
coleções de consoles que possuem tecnologias e períodos de comercialização semelhantes são chamadas de 'geração de vídeo games', conforme quadro 3 abaixo.

Quadro 3-Gerações de Vídeo Games em ordem cronológica

\begin{tabular}{c|c|c}
\hline 1a Geração & 2a Geração & 3a Geração \\
$1972-1977$ & $1978-1983$ & $1983-1992$ \\
\hline 4a Geração & $\mathbf{5}$ a Geração & 6a Geração \\
$1987-1996$ & $1993-1999$ & $1998-2004$ \\
\hline 7a Geração & $\mathbf{8}$ Geração & 9a Geração \\
2004 - 2011 & $2011-2017$ & 2017 - presente \\
\hline
\end{tabular}

Fonte: adaptado de Bit by Bit: How Video Games Changed the World (ERVIN, 2017)

A cada geração, é perceptível a evolução de tecnologias compatíveis as disponíveis no tempo de seus lançamentos. Enquanto a primeira geração era executada em um plano preto com as partes do jogo em branco, na atualidade é possível recriar efeitos cinematográficos com tamanha precisão que os games mais parecem filmes live action. As plataformas contemporâneas também possibilitam a conexão com a internet, criando assim mundos virtuais para jogos de multidão em que os avatares dos jogadores podem interagir com milhões de outros jogadores, de um mesmo país, continente ou do mundo, de acordo com as configurações estabelecidas pela empresa responsável pela distribuição do game.

Hoje, os vídeo games são produtos amplamente difundidos com diversos títulos, executados por muitas plataformas, com tecnologias diversas, atendendo aos mais diversos públicos. Por fazerem parte do cotidiano de muitos usuários, acabam por meio destes influenciando a cultura popular, e também a utilizam para criar jogos inspirados em narrativas do cotidiano, gerando mais interesse das pessoas.

Na simulação de um jogo, o usuário pode assumir inúmeros papeis, que variam de personagens advindos do imaginário a esportistas da vida real, em desafios impossíveis de serem vivenciados na realidade, como uma aventura em um universo paralelo ou vencer um campeonato do seu esporte favorito.

Por ser uma das formas de entretenimento mais importante da contemporaneidade, os games foram considerados a 10 arte. $\mathrm{E}$ assim como as demais formas de arte, investigar a sua história é investigar não só a evolução dos video games, mas também o desenvolvimento de uma parte da sociedade, seus usuários assíduos, conhecidos como Gamers.

\section{Cultura, Sociedade e Mercado Gamer}

Quando o Museu de Arte Moderna de Nova lorque (MoMa) iniciou sua exposição de games em 2012, com um acervo inaugural de 16 peças, e com perspectivas de completar até 40 peças, a designação dos games como a 10 a arte se solidificou. De acordo com a curadora sênior do museu, Paola Antonelli (2012) "Os videogames são artefatos que realmente representam a cultura e o design da nossa época [...] os games são obras de arte que ganham vida nas mãos dos jogadores". Ao referenciar os videogames como arte, aceita-se que os mesmos não apenas contextualizam a 
cultura e a sociedade da época, como também são influenciadores destes cenários.

No âmbito mercadológico, os games são um fenômeno inegável. Em 2016, enquanto o cinema, a 7a arte, comemorava seu recorde de bilheteria com arrecadação de USD $\$ 38,6$ bilhões (MPAA, 2017), o mercado de games arrecadou USD $\$ 101,1$ bilhões entre os jogos de console, computador e celular (NewZoo, 2017). A importância destes números de mercado pode ser traduzida ainda em impacto social: de acordo com a consultoria NewZoo (2017) existem cerca de 2.2 bilhões de gamers, somando-se todas as plataformas, ou seja, quase $1 / 3$ da população mundial. Esta ampla difusão dos video games são responsáveis por fenômenos contemporâneos únicos. Cardoso (2016) explica que os artefatos, produtos desenvolvidos pelo homem, nascem com o sentido e o valor do tempo e da razão em que foram criados, e que estes artefatos passam então a influenciarem o seu tempo. É como um ciclo que se retroalimenta a partir da criação do artefato: a inspiração para a idealização, desenvolvimento e fabricação do artefato acontece dentro de um cenário cultural, social e mercadológico; e este artefato, por sua vez, pode influenciar estes mesmos cenários, dando origem a novas cenas culturais, sociais e mercadológicas, e talvez novos produtos.

Para o cenário gamer, uma analogia possível é a do futebol e todos os fenômenos que ele desencadeou: fãs, produtos licenciados, novas profissões (o jogador de futebol), novas mídias (patrocínios), conteúdo para entretenimento, e outros. No quadro 4, são apresentados alguns exemplos de fenômenos oriundos dos games, e gamers que estão sendo investigados nesta dissertação.

Quadro 4 - Fenômenos Gamers

i) Cadeia Produtiva dos Games A partir dos video games, criou-se uma indústria game que arrecada mais de 101,1 bilhões de dólares.

ii) Empregos

Esta indústria demanda mão de obra especializada, são engenheiros das áreas de hardware e software, programadores, roteiristas, animados, designer, gestores, e tantas outras.

iii) Educação

Mão de obra especializada exige capacitação. Um exemplo disso é que só no Brasil foram criados cerca de 50 cursos de graduação relacionados a desenvolvimento de jogos eletrônicos. Esta demanda deve crescer, uma vez que o Brasil é o 4으 maior mercado gamer mundial, mas considerado subdesenvolvido na produção de games (GAMER REPORTER, 2017).

iv) Gamers

Os usuários deste produto são por si só um fenômeno. São cerca de 2.2 bilhões de jogadores que demandam não apenas por mais games, mas também por produtos relacionados. Os games deram origem ou influenciaram novas personas, como o 'nerd', o 'geek', e no Brasil o que se chama 'guri de apartamento' (crianças que passaram sua infância em lugares fechados, longe das ruas, geralmente de grandes cidades, tornando-as uma geração totalmente diferentes das gerações anteriores).

v) Mercado Fã

É comum encontrar alguém vestido com a camiseta do seu time de futebol preferido, ou banda preferida. Será cada vez mais comum o surgimento de produtos que caracterizem o gamer como gamer, ou que atendam suas necessidades gamers além dos games. Produtos: roupas, canecas, chaveiros, e demais itens de uso pessoal; acessórios para melhor jogar, como mouses, teclados, mousepads e outros; livros, filmes, canal online específico (a Twitch, espécie de YouTube para transmissão de games, jogados por profissionais ou amadores), programas de tv e 
outras mídias de entretenimento; entre outras.

vi) Cenário E-sport

Alguns games já são chamados de Esportes Eletrônicos, promovendo campeonatos com premiações milionárias, atletas profissionais, espectadores/torcidas, entre outras. Há uma discussão sobre ser ou não ser caracterizado como esporte, no entanto, eles geram os mesmos fenômenos do futebol neste sentido: o jogo Leagues Of Legends, por exemplo, é o mais jogado do mundo e possui campeonatos no Brasil e outros países, e um campeonato mundial com patrocinadores como Coca Cola, Samsung e outras grandes marcas, transmissão pela Twitch e por canais de esportes convencionais como a ESPN, devido ao seu sucesso em audiência.

vii) Gamificação

Este termo recente se refere ao uso dos princípios de um game para transformar outras atividades da vida prazerosas, conforme teoria do fluxo de Mihály Csíkszentmihályi, também conhecida como a "engenharia da felicidade". Livros de "gamefication" surgem em todas as sessões, de autoajuda a estratégias de Recursos Humanos para desenvolvimento profissional e organizacional.

Fonte: primária com base em Ervin (2017) e McGonigal (2012)

São tantos fenômenos que seria difícil aborda-los em sua totalidade. No entanto, dentre todos estes citados e outros exemplos possíveis, é a partir da gamificação que se inicia a reflexão sobre os games na construção do futuro.

\title{
4 A importância dos Games na Construção Futuro
}

$\mathrm{Na}$ abordagem da gamificação, os princípios dos games podem ser associados ao Design enquanto ferramenta para análise de problemas e proposição de soluções, pois

\begin{abstract}
ao transformar um problema real em um obstáculo voluntário, ativamos um interesse, uma curiosidade, uma motivação, um esforço e um otimismo mais genuínos, coisa que dificilmente seríamos capazes de fazer de outra maneira. Conseguimos mudar nossos comportamentos da vida real no contexto de um jogo ficcional exatamente porque não há nenhuma pressão negativa em torno da decisão da mudança. Somos motivados unicamente pelo estresse positivo e por nosso próprio desejo de nos envolver com um jogo de uma forma mais gratificante, bem-sucedida, social e significativa (McGonigal, p. 310, 2012).
\end{abstract}

Quando o futuro é analisado por meio da ótica do Design, como ciência que estuda o mundo criado pelo homem (CROSS, 1982), pode-se adotar a premissa de que os novos paradigmas que serão enfrentados no futuro não são frutos do acaso. No livro Homo Deus, do pesquisador e professor de história Yuval Hahari (2016) é contextualizo os grandes avanços da humanidade, tantos nos cenários socioeconômicos como também no desenvolvimento da tecnologia e a relação com contemporaneidade. Assim, a visão sobre o futuro apresentada pelo autor é uma sequência de fatos estimados logicamente a partir das consequências resultantes das tecnologias e modos de viver atuais, que podem ou não se concretizarem.

Harari (2016) salienta que o século XXI se caracterizará pela obsolescência do liberalismo e diante deste cenário prever, (i) mudanças no sistema político, baseadas na diminuição da utilidade humana, tanto na economia quanto na força militar; (II) a perda de valor da individualidade; (III) e por fim, o surgimento de uma casta de super-humanos. A queda do liberalismo pode por em riscos 
conceitos como democracia, livre mercado e direitos humanos. A tecnologia tem explicitado a separação da consciência e da inteligência, qualidades que andaram juntas até então. Mas que o avanço da resolução de problemas complexos, alcançados pelos algoritmos, está apontando também para a separação do gênero humano, por um lado, a formação de massa sem empregos, o que Harari prefere chamar de uma 'massa de inúteis' e no seu oposto, uma pequena elite de superhumanos aprimorados.

O avanço da inteligência artificial, tem permitido a substituição de muitas atividades humana. A inteligência artificial gesta, portanto, a passos largos, a criação de uma classe não trabalhadora, o que tem produzido preocupação global e levado os cientistas sociais à debruçassem sobre este problema no intuito de procurar entender os efeitos mentais e comportamentais que a 'não empregabilidade' pode causar em grandes grupos que fazem parte de uma sociedade aonde o trabalho vai além da manutenção e produção de bens, chega a ter um cunho religioso, como destaca Weber (2004, p. 47-48) a ação social no capitalismo moderno:

[...] é um intenso cosmos em que o indivíduo já nasce dentro e que para ele, ao menos enquanto indivíduo, se dá como um fato, uma crosta que ele não pode alterar e dentro da qual tem que viver. Esse cosmos impõe ao indivíduo, preso nas redes do mercado, as normas de ação econômica. $O$ fabricante que insistir em transgredir essas normas é definitivamente eliminado, do mesmo modo que o operário que a elas não possa ou não queira se adaptar é posto no olho da rua como desempregado[...]O capitalismo hodierno, dominando de longa data a vida econômica, educa e cria para si mesmo, por via da seleção econômica, os sujeitos econômicos - empresários e operários - que necessita.

Junto à capacidade demostrada na resolução de problemas complexos, pelos algoritmos, se inserem as promessas tradicionais do humanismo que sempre seduziram a humanidade; a tecnologia agora reforça estas promessas, quais sejam, paz, felicidade e vida eterna, mas com um novo apelo, sem a necessidade do asceticismo necessário em muitas religiões; o paraíso a ser alcançado é terreno e agora. Os homens do presente e do futuro próximo podem apenas trocar os seus deuses pela tecnologia e usem de forma incondicional os algoritmos, definam suas vidas, assim como os gregos usavam os oráculos. Quando até mesmo a biologia é abordada desta forma, a morte passa a ser considerada uma falha técnica, os códigos do DNA poderão, em breve, ser modificados evitando, desta forma, a doença e prorrogando a morte ao infinito. Para Harari os paradigmas, desta nova religião, estão postos. Nela se troca o antropocentrismo, pelo 'datocentrismo', onde o mundo composto por um fluxo de informações, que vão do cosmos aos organismos vivos, das coisas às coisas, do cosmo ao cosmo, tudo intermediado pela tecnologia, um mundo onde os dados fluem, de um ponto a outro, independente do controle humano, um mundo onde tanto a fabricação, como a logística acontecem de forma autônomas, respondendo a dados gerados a partir de dados.

As questões propostas pelo Harari (2016) e relacionadas ao trabalho vão ao encontro da discussão sobre o por quê jogamos? Na abordagem de McGonigal e Csíkszentmihályi (2012). Harari (2016) afirma que a tecnologia levará a sociedade a viver em uma era pós trabalho. Partindo desta afirmação, no futuro próximo, as máquinas e a inteligência artificial tomarão conta da maior parte das atividades laborais produtivas e os humanos, em uma visão utilitarista, serão divididos entre aqueles que formam um grupo de mão de obra extremamente especializada, com capacidade cognitiva para analisar e interagir com os algoritmos que solucionam os problemas laborais, e a maior parte da população definida pelo historiador como massa inútil, pessoas que não possuem habilidades cognitivas para o trabalho, já que as suas aptidões físicas foram totalmente substituídas por soluções em automação. Os elementos para a concretização deste futuro já existem na 
sociedade contemporânea.

Johnson (2012) aborda os efeitos dos games, da televisão, do cinema e de outras formas de entretenimento contemporâneos como essenciais para o homem moderno, e apresenta o hábito de jogar vídeo game como fundamental para o desenvolvimento cognitivo necessário para que o jogador possa interagir com todas as demais tecnologias a sua volta, para atividades de lazer ou profissionais. $\mathrm{O}$ autor faz uma metáfora com o hábito de ler livros: como os livros estão bastante distribuídos e seus benefícios são de conhecimento do público leitor e não leitor, entende-se que é uma atividade importante e recomendada, no entanto, nem sempre foi assim. Aqueles que liam já foram vistos como uma massa de inúteis, já que não desempenhavam o trabalho necessário a época, e o conhecimento intelectual era menos utilizado para fins produtivos do que as habilidades motoras que exigiam força e preparo físico, relacionadas a prática de esportes.

Os games desenvolvem, não apenas as habilidades cognitivas, quando relacionados ao uso de tecnologias, mas desenvolve a lógica e o auto aprendizado para superar os desafios inerentes ao próprio jogo. Os games desenvolvem a capacidade analítica e estratégica similar e necessárias para resolver os problemas da vida real (JOHNSON, 2012; MCGONIGAL, 2012).

Se o trabalho ocupa e dignifica a vida do homem, fazendo parte da sua natureza e se a felicidade das pessoas está relacionada aos momentos de fluidez, ou seja, o sentimento de superar os obstáculos impostos no trabalho e pelo trabalho, o que esperar de uma sociedade pós trabalho, em que a maior parte das pessoas não está aptas ou qualificadas, ou ainda representam excesso de mão de obra frente a poucas posições necessárias?

Uma vez que pessoas totalmente desocupadas estão mais susceptíveis ao tédio e a ansiedade, bem como outras doenças psíquicas mais danosas como o caso da depressão, Harari (2016) sugere duas possíveis alternativas, quais sejam, a distribuição de drogas ou o entretenimento escapista como os games, pois estes, além de entreter, podem servir como o trabalho árduo necessário para que acessem o estado de fluidez, proposto por Csíkszentmihályi (apud MCGONIGAL, 2012) para um grupo de pessoas que neste estado, não podem contribuir com o bem-estar coletivo. Esta posição marca

o reconhecimento da função social do jogo alinhando-se a outras funções já estudadas, como a biológica, a educativa ou a estética. Atualmente esta atividade se tornou a principal maneira de ocupação do tempo livre para as grandes massas trabalhadoras “...exercendo, portanto, a função de corrigir e equilibrar as atividades sociais, o que ainda precisa ser mais bem estudado." (ABBAGNANO, 1998. p. 589).

Com o futuro visto como consequência das ações do presente é uma premissa para a concretização do próprio futuro imaginado. O cinema e a literatura, neste sentido, colaboram com esta imaginação. No filme Matriz (1999), por exemplo, inspirado nas teorias de Simulacros e Simulações (BAUDRILLARD, 1991), os personagens circulavam entre dois mundos, o 'real' em que poucas pessoas conseguiam habitar conscientemente, e o 'simulado' (a matrix) onde a maior parte das pessoas viviam. Como a matrix, uma hiper-realidade construída de forma virtual era perfeitamente igual a realidade, as pessoas não conseguiam discernir entre o real e simulado.

Já o livro Jogador Número 1 (em inglês "Ready Play One"), do autor Ernest Cline (2012), é ambientado em um futuro próximo, em mundo poluído e inseguro, em que a maior parte da população tem dificuldades de sobreviver com uma qualidade adequada de vida. Neste futuro, existe um console composto por uma luva e um visor capaz de simular as ações do jogador dentro 
da realidade virtual do jogo chamado Oasis - similar a matrix do filme - onde o mundo virtual se confunde com a realidade. Neste universo criado pelo autor, a plataforma é tanto um jogo de imersão, semelhante ao estilo $\mathrm{MMORPG}^{2}$, como também um espaço de convivência global.

Mesmo que este console ainda esteja disponível, é importante observar que os vídeo games atuais são compatíveis com diversos apetrechos de realidade aumentada, e que a indústria de games a cada ano anuncia novas tecnologias para games cada vez mais imersivos.

Por fim, a participação dos games nesta construção de futuro pode se dar não só pelo desenvolvimento laboral do jogador, ou do entretenimento envolvente que tornam os jogadores mais felizes e otimistas, mas também como meio para o desenvolvimento de um mundo melhor. McGonigal (2010), ao tentar explicar, como jogar vídeo games pode ser uma ferramenta para melhorar o mundo, faz o seguinte questionamento, se as pessoas no planeta jogam coletivamente 3 bilhões de horas por semana, quanto do trabalho árduo poderia contribuir para um mundo melhor se os games gerassem soluções?

\section{Considerações Finais}

Este artigo, trouxe uma reflexão sobre a influência dos games como recorte da dissertação em andamento no Mestrado Profissional em Design da Universidade da Região de Joinville (UNIVILLE), cujo objetivo foi fazer uma reflexão sobre a influência dos games na construção do futuro. Para tanto buscou-se articular o conceito de jogo e sua função em um possível cenário futuro proposto por Harari (2016); refletiu-se, da mesma forma, sobre como os jogos interagem e contribuem com possíveis cenários sociais, culturais e mercadológicos propostos.

Sobre o verbo jogar, constatou-se que não há como estipular ao certo a origem dos jogos, pois os mesmos precedem a cultura, ou seja, as crenças e hábitos humanos. No entanto, o ato de jogar é uma parte essencial da construção do homem por estimular a imaginação, a estratégia e outras habilidades cognitivas, sendo a chave para o desenvolvimento intelectual das pessoas.

Enquanto a definição de 'jogo' permanece relacionada à virtude e ao prazer, a significação de 'trabalho' passa por mutações conforme os paradigmas de cada época. $\mathrm{O}$ 'trabalho', entendido como atividade manual, árdua e obrigatória, tido antes como o oposto ao 'jogo', ao lúdico e prazeroso, na contemporaneidade passa a ser percebido de outras maneiras, e muitas vezes se assemelha ao 'jogo'.

As simulações realizadas sobre jogos, em suas diferentes modalidades e objetivos, levam o usuário a um estado de 'fluidez' muitas vezes impossível na realidade. Se as pessoas se alegram e se motivam com a superação de desafios, a realidade torna-se menos estimulante em relação aos jogos por não apresentar metas e objetivos claros, feedbacks consistentes sobre a evolução no processo, ou mesmo por serem uma obrigação, e não atividade voluntária. Enquanto um trabalho profissional pode eventualmente apresentar estas características, os jogos estimulam por serem assim por essência.

Este estado de 'fluidez' dos jogos incentivam o usuário a buscarem o aprimoramento de suas habilidades em níveis mais elevados do jogo, ou ainda a buscarem novos jogos. Como as simulações

\footnotetext{
${ }^{2}$ MMORPG: Massive Multiplayer Online RPG, neste estilo os jogadores simulam serem personagens para vivenciar o universo do próprio jogo, com missões, interações e ganho de experiência que eleva o nível do mesmo.
} 
geradas, os jogos apresentam-se como uma alternativa mais atraente aos ofícios da vida real, não só por oferecerem desenvolvimento, mas por também serem uma forma de lazer e entretenimento, passam a ser explorados comercialmente em uma nova plataforma: os vídeo games.

Os vídeo games, também conhecidos como jogos eletrônicos, viabilizaram a execução de um jogo por meio de consoles (aparelho de vídeo game), celulares, computadores e outras plataformas eletrônicas/digitais e possibilitaram aos usuários usufruir de diversas simulações, como aventuras, corridas, prática de esportes, investigações, dentre outras. Evoluindo com as tecnologias de suas épocas de lançamentos, os games também promoveram a evolução da experiência dos usuários, disponibilizando gráficos, dinâmicas e desafios cada vez maiores e melhores, possibilitando ainda interação com um ou milhões de outras pessoas simultaneamente em uma mesma simulação.

Atualmente, os games possuem um grande público e assim, consequentemente, uma grande indústria. Esta indústria gamer não só se baseia em diferentes culturas, antigas ou contemporâneas, para criação de seus produtos, como também influência a cultura por meio da alimentação de repertório de seus usuários. Reconhecer os vídeo games como a 10aa arte é o mesmo que reconhecer que, assim como as demais artes, eles são tanto resultados como influenciadores do seu tempo, sendo estes resultados e influências fenômenos gerados por eles.

Esta contextualização dos jogos e dos jogos eletrônicos é necessária para analisar os possíveis desdobramentos dos jogos na construção do futuro. Na abordagem deste artigo, foi descrito um paradigma do futuro proposto por Hahari (2016) sobre o trabalho. Em uma sociedade pós trabalho, dominada por máquinas em substituição ao trabalho físico e inteligência artificial em substituição aos trabalhos cognitivos. Serão necessários poucos os postos de trabalhos humanos, e estes reservados àqueles que possuírem habilidades cognitivas suficientemente desenvolvidas para interagir com a inteligência artificial.

Assim, no cenário proposto, a maior parte da humanidade, seria incapacitada de ocupar posições de trabalho para fins produtivos, ficando, portanto, desocupada, susceptível a ansiedade e ao tédio, sentimentos negativos que podem influenciar atitudes também negativas. Os games, neste contexto, podem servir de duas maneiras: como importante forma de capacitação cognitiva, auxiliando as pessoas no desenvolvimento de suas habilidades; ou ainda como substituição ao trabalho, por meio de jogos que forneçam entretenimento e momentos de 'fluidez' aos seus usuários.

No entanto, como toda reflexão sobre o futuro são retratos imaginários de quem se propõe a fazê-lo, é importante ressaltar que estas suposições podem ou não se concretizarem, dependendo dos problemas e soluções resultantes das ações do presente. Embora os jogos e os games evoluam com a tecnologia, os mesmos podem ser utilizados desde agora para a construção de um futuro melhor, seja por meio de sua capacidade de estimular o desenvolvimento de seus usuários, seja pela contribuição que suas narrativas podem promover na cultura popular, ou seja pela utilização eficiente dos jogos para resolver problemas da vida real. 


\section{Referências}

ABBAGNANO, Nicola. Dicionário de filosofia. São Paulo: Martins Fontes, 1998

ALVES,L.;BIANCHIN,M.A.,2010. 0 jogo como recurso de aprendizagem. Disponível em: http://pepsic.bvsalud.org/scielo.php?script=sci_arttext\&pid=S0103-84862010000200013. Acesso em: 26 mar. 2018.

ANTONELLI, P. Video Games: 14 in the Collection, for Starters. Nova lorque: Museum of Modern Art. Disponível em: <https://www.moma.org/explore/inside_out/2012/11/29/video-games-14-inthe-collection-for-starters/>. Acesso em: 8 nov. 2017

BAUDRILLARD, J. Simulacros e Simulações. Lisboa: Relógio D'água, 1991.

CARDOSO, R. Design para um mundo complexo. São Paulo: Cosac Naify, 2012.

CLINE, E. Jogador No 1. São Paulo: Leya, 2012.

CROSS, N. Designerly ways of knowing. Design Studies, v. 3, n. 82, p. 221-227, 1982.

ERVIN, A. Bit by Bit: How Video Games Transformed Our World. Nova lorque: Basic Books, 2017.

GAMER REPORTER. GUIA - ONDE ESTUDAR DESENVOLVIMENTO DE GAMES NO BRASIL. Disponível em: <http://gamereporter.uol.com.br/desenvolvimento-dALVES, L.digitais/>. Acesso em: 9 nov. 2017.

HARARI, Y. N. Homo Deus: Uma breve história do amanhã. 1a ed. São Paulo: Companhia das Letras, 2016.

HUIZINGA, J. Homo ludens. São Paulo: Perspectiva, 2005.

JOHNSON, S. Tudo que é ruim é bom para você Como os games e a TV nos tornam mais inteligentes. Rio de Janeiro: Zahar, 2012

LUZ, A. Vídeo Games: História, Linguágem e Expressão Gráfica - Do nascimento à consolidação do vídeo game como linguagem. São Paulo, SP: Blucher, 2010.

MCGONIGAL, J. A Realidade em Jogo. 1a edição. Rio de Janeiro, RJ: Best Seller, 2012.

MCGONIGAL, J. Gaming Can Make a Better World?. TED, 2010. Disponível em: $<$ https://www.ted.com/talks/jane_mcgonigal_gaming_can_make_a_better_world?language=ptbr\#t-35695>

MPAA. 2016 Theatrical Market Statistics ReportMpaa.Org. Washington D.C: [s.n.]. Disponível em: <http://www.mpaa.org/wp-content/uploads/2017/03/MPAA-Theatrical-Market-Statistics2016_Final-1.pdf>.

NEWZOO. The Brazilian Gamer 2017. Disponível em: <https://newzoo.com/insights/infographics/the-brazilian-gamer-2017/>. Acesso em: 10 nov. 2017. WEBER, Max. A ética protestante e o "espirito" do capitalismo. São Paulo: Companhia das Letras, 2012 